\title{
Effect of adding polyethylene glycol and polyvinylpyrrolidone on organic matter digestibility, metabolizable energy and net energy for lactation of grape pomace using in vitro gas production technique
}

M Besharati ${ }^{1,2}$, A Taghizadeh ${ }^{1}$

${ }^{1}$ University of Tabriz, Tabriz, East Azarbyjan, Islamic Republic of Iran

${ }^{2}$ Payame Noor University of Benis, Shabestar, Islamic Republic of Iran

Email:ataghius@yahoo.com

Introduction A major constraint to increasing livestock productivity in developing countries is the scarcity and fluctuating quantity and quality of the year-round supply of conventional feeds. In order to meet the projected high demand of livestock products and to fulfill the future hopes of feeding the millions and safeguarding their food security, the better utilization of non-conventional feed resources which do not compete with human food is imperative (Besharati et al., 2008). The annual amount of produced agro-by-products in Iran is generous, whereas, production of grape exceeds 2.87 billion tonnes/year, that proportion of grape yield is used for production of grape juice. In this process, grape pomace is produced in high level (Besharati and Taghizadeh, 2009). There is little information available on the nutritive value of grape pomace. Although grape pomace is low in ME, it has been used in diets of ruminants fed close to maintenance ME levels, especially in sheep (Abel \& Icking, 1984). However, inclusion of grape pomace in the diet reduced digestibilities of the diet (Baumgartel et al., 2007). Yinrong Lu \& Yeap Foo (1999) reported that grape pomace tannins have adverse effects on nutrient utilization, and are toxic at high intake levels (Reed, 1995) due to their ability to bind proteins, minerals and carbohydrates (McSweeney et al., 2001). Tannins are the most widely occurring anti-nutritional factor in non-conventional feeds. The aim of this study was to determine the effect of adding polyethylene glycol and polyvinylpyrrolidone on organic matter digestibility, metabolizable energy and net energy for lactation of grape pomace using in vitro gas production technique.

Material and methods The chemical composition of grape pomace was determined using the methods recommended by AOAC (1999). The NDF and ADF concentrations were determined using the methods of Van Soest et al. (1991). Total phenolics (TP) were measured using the Folin Ciocalteau method (Makkar, 2000). Total tannin (TT) was determined after adding insoluble polyvinylpyrrolidone and reacting with Folin Ciocalteau reagent (Makkar, 2000). Tannic acid was used as the standard to express the amount of TP and TT. Ruminal fluid was collected approximately $2 \mathrm{~h}$ after morning feeding from 2 cannulated sheep. Gas production was measured by Fedorak and Hrudy (1983) method. Approximately 300 mg of dried and ground $(2 \mathrm{~mm})$ grape pomace sample was weighed and placed into serum bottles in the absence and presence $(300 \mathrm{mg})$ of PEG or PVP. The gas production was recorded after $24 \mathrm{~h}$ of incubation. Total gas values were corrected for the blank incubation, and reported gas values are expressed in $\mathrm{ml}$ per 0.02 gram of DM. The organic matter digestibility (OMD), ME and $\mathrm{NE}_{\mathrm{L}}$ contents of forages were estimated by the method of Menke and Steingass (1988). The short chain fatty acid content calculated using equation $\mathrm{SCFA}_{(\mathrm{mmol})}=0.0222 \mathrm{GP}-0.00425$. The data at the different times was analyzed using completely randomized design by the GLM procedure of SAS Institute Inc (2002).

Results The chemical compositions of grape pomace are presented in Table 1. Effect of adding PEG and PVP on OMD, ME, GP, SCFA and $\mathrm{NE}_{\mathrm{L}}$ are shown in Table 2. Within the treatments, treatments with PEG or PVP had the highest OMD, $\mathrm{ME}, \mathrm{GP}, \mathrm{SCFA}$ and $\mathrm{NE}_{\mathrm{L}}$ values $(\mathrm{P}<0.05)$. Adding polyethylene glycol and polyvinylpyrrolidone to grape pomace increased the organic matter digestibility, metabolizable energy, short chain fatty acid and net energy for lactation of grape pomace.

Table 1 The chemical composition of grape pomace (\%DM)

\begin{tabular}{lllllllll}
\hline \hline Feed & DM & CP & NDF & ADF & Crude fat & OM & Total phenols & Total tannins \\
\hline Grape pomace & 93.3 & 6.62 & 18.7 & 18.4 & 1.41 & 87.7 & 3.01 & 2.27 \\
\hline \hline
\end{tabular}

Table 2 Effect of adding PEG and PVP on OMD, ME, GP, SCFA and $\mathrm{NE}_{\mathrm{L}}{ }^{*}$

\begin{tabular}{llllll}
\hline \hline \multirow{2}{*}{ Treatments } & \multicolumn{5}{l}{ Estimated parameters } \\
\cline { 2 - 6 } & $\mathrm{GP}_{(\mathrm{m} / 0.2 \mathrm{~g} \mathrm{DM})}$ & $\mathrm{OMD}_{(\%)}$ & $\mathrm{ME}_{(\mathrm{MJ} / \mathrm{kg} \mathrm{DM})}$ & $\mathrm{NE}_{\mathrm{L}(\mathrm{Mcal} / \mathrm{b})}$ & $\mathrm{SCFA}_{(\mathrm{mmol})}$ \\
\hline Grape pomace & $46.3^{\mathrm{b}}$ & $56.1^{\mathrm{b}}$ & $8.54^{\mathrm{b}}$ & $0.237^{\mathrm{b}}$ & $1.024^{\mathrm{b}}$ \\
Grape pomace + PEG & $55.6^{\mathrm{a}}$ & $64.3^{\mathrm{a}}$ & $9.79^{\mathrm{a}}$ & $0.254^{\mathrm{a}}$ & $1.229^{\mathrm{a}}$ \\
Grape pomace + PVP & $55.3^{\mathrm{a}}$ & $64.1^{\mathrm{a}}$ & $9.76^{\mathrm{a}}$ & $0.253^{\mathrm{a}}$ & $1.223^{\mathrm{a}}$ \\
SEM & 0.491 & 0.067 & 0.436 & 0.0009 & 0.0109 \\
\hline \hline
\end{tabular}

* The means within a column without common letter differ $(p<0.05)$.

Conclusions The increase in OMD, ME, GP, SCFA and $\mathrm{NE}_{\mathrm{L}}$ in the presence of PEG and PVP is possibly due to an increase in the available nutrients to rumen micro-organisms, especially the available nitrogen.

Acknowledgement This study was funded by University of Tabriz, Tabriz, Iran.

\section{References}

Besharati, M. and A. Taghizadeh, 2009. Journal of Animal Feed Science and Technology. 152, 198-203.

Besharati, M., A. Taghizadeh, H. Janmohammadi and G.A. Moghadam. 2008. American Journal of Animal and Veterinary Science 3, 7-12.

SAS Inc., 2002. SAS User’s Guide: Statistics. Statistical Analysis Systems Institute Inc. Cary NC. 